\title{
Malvaceae s. str. na Reserva Rio das Pedras, Mangaratiba, Rio de Janeiro, Brasil
}

\author{
Malvaceae s. str. of the Rio das Pedras Reserve, \\ Mangaratiba, Rio de Janeiro, Brazil
}

Massimo G. Bovini ${ }^{1}$

\begin{abstract}
Resumo
A Reserva Rio das Pedras está localizada no sul fluminense e pertence a um fragmento de floresta pluvial Atlântica, possuindo cerca de 1.360 ha. Foi realizado um estudo morfológico e taxonômico das Malvaceae s. str., no qual registrou-se 13 espécies pertencentes a seis gêneros (Abutilon, Malvastrum, Pavonia, Sida, Sidastrum e Urena), sendo Sida o gênero com maior número de espécies. São apresentadas chave de identificação, descrições e ilustrações das espécies.

Palavras-chave: florística, Rio de Janeiro, taxonomia.
\end{abstract}

\begin{abstract}
The Rio das Pedras Reserve is located in southern Rio de Janeiro state and represents a fragment of the Atlantic rain forest, with about 1,360 ha. A morphological and taxonomic study of the Malvaceae s. str. was carried out, registering 13 species belonging to six genera (Abutilon, Malvastrum, Pavonia, Sida, Sidastrum and Urena), with Sida the most frequent. A key for identification, descriptions and illustrations of the species are presented. Key words: floristic, Rio de Janeiro, taxonomy.
\end{abstract}

\section{Introdução}

Malvaceae s. str. pertence à ordem Malvales (sensu Cronquist 1988), juntamente com outras três famílias estreitamente relacionadas, Bombacaceae, Sterculiaceae e Tiliaceae. Entretanto esta composição sempre foi alvo de conflitos de circunscrição entre vários autores (Fryxell 2007). Judd \& Manchester (1997), a partir de caracteres morfológicos e químicos, não corroboram com a subdivisão da Ordem Malvales sensu Cronquist (1988), apresentando Bombacaceae, Sterculiaceae e Tiliaceae como grupos parafiléticos, sendo apenas Malvaceae um grupo monofilético. Com base nesses resultados, a inclusão das Bombacaceae, Tiliaceae e Sterculiaceae, nas Malvaceae "expandida", ou sensu lato, foi sugerida em APG (1998).

As Malvaceae s. str. são amplamente distribuídas em todo o mundo, ocorrendo predominantemente nas regiões tropicais e raramente encontradas em altas elevações. Possuem aproximadamente 100 gêneros e cerca de 1.700 espécies (Fuertes 1985). No Brasil,
Bovini et al. (2010) listaram 66 gêneros e 746 táxons para as Malvaceae, sendo 30 gêneros distribuídos em 393 táxons de Malvoideae (= Malvaceae s.str.).

Quanto à importância econômica, possuem representantes de considerável valor, sendo utilizadas na ornamentação em todo o mundo, como espécies de Abutilon Mill., Alcea L., Hibiscus L., Malvaviscus Fabr. e Thespesia Sol., ou ainda, por serem utilizados na indústria têxtil, como espécies de Gossypium L. (algodão) e Urena L. (juta).

No estado do Rio de Janeiro, embora remanescentes vegetacionais estejam bem preservados em Unidades de Conservação, suas riquezas florísticas são ainda pouco conhecidas. Tendo em vista a escassez de estudos em Malvaceae s. str. para o estado do Rio de Janeiro, este trabalho teve por objetivo analisar sob o ponto de vista morfológico e taxonômico as espécies de Malvaceae s. str. na Reserva Rio das Pedras, um importante remanescente de Mata Atlântica ainda carente de informações sobre sua flora. 


\section{Material e Métodos}

A Reserva Rio das Pedras (RRP) está situada no lado atlântico da Serra do Mar, inserida no Maciço da Serra da Bocaina, localizado-se no município de Mangaratiba, estado do Rio de Janeiro, entre as coordenadas $22^{\circ} 59^{\prime} \mathrm{S}$ e $44^{\circ} 05^{\prime} \mathrm{W}$. Possui cerca de 1.360 ha distribuídos em altitudes que variam de 20 a 1.050 metros. Apresenta diferentes estágios de sucessão, representando um dos poucos remanescentes de floresta pluvial atlântica neste estado (Carvalho \& Bovini 2006). O clima é subquente (Nimer, apud Vidal 1995) com temperatura médias anuais de $22^{\circ} \mathrm{C}$ e temperatura máxima absoluta de $38^{\circ} \mathrm{C}$.

No que diz respeito a hidrografia, a Reserva é delimitada em seu contorno externo pela bacia do Rio Grande, cuja linha de divisor de águas é bem definida e abrupta (Fig. 1).

Foram realizadas expedições de campo durante cinco anos, no período de 1996-2001, na RRP. Nesta, em diversas trilhas, foram coletadas sempre que possível, amostras botânicas com flores e/ou frutos. O material foi herborizado segundo técnicas usuais e incorporado aos herbários RUSU e duplicatas no RB (siglas de acordo com Thiers, continuamente atualizado).

No tratamento taxonômico adotou-se a classificação da ordem Malvales de Cronquist (1988), seguindo trabalhos taxonômicos anteriores na RPP de Quinet \& Andreata (2005) e Carvalho \& Bovini (2006). Os táxons apresentados nas descrições seguem a ordem alfabética para gêneros e espécies. As descrições dos táxons foram restritas aos materiais coletados na RPP e, quando necessário, complementadas com materiais adicionais.

\section{Resultados e Discussão}

Neste estudo foram reconhecidas 13 espécies de Malvaceae s. str., distribuídas em seis gêneros: Abutilon, Malvastrum, Pavonia, Sida, Sidastrum e Urena. Destes, Sida mostra-se o mais abundante com seis espécies seguido por Abutilon, com três.

\section{Malvaceae s. str.}

Subarbustos ou arbustos eretos ou decumbentes. Ramos cilíndricos, raramente aplanados, pubescentes, pubérulos, hirsutos,

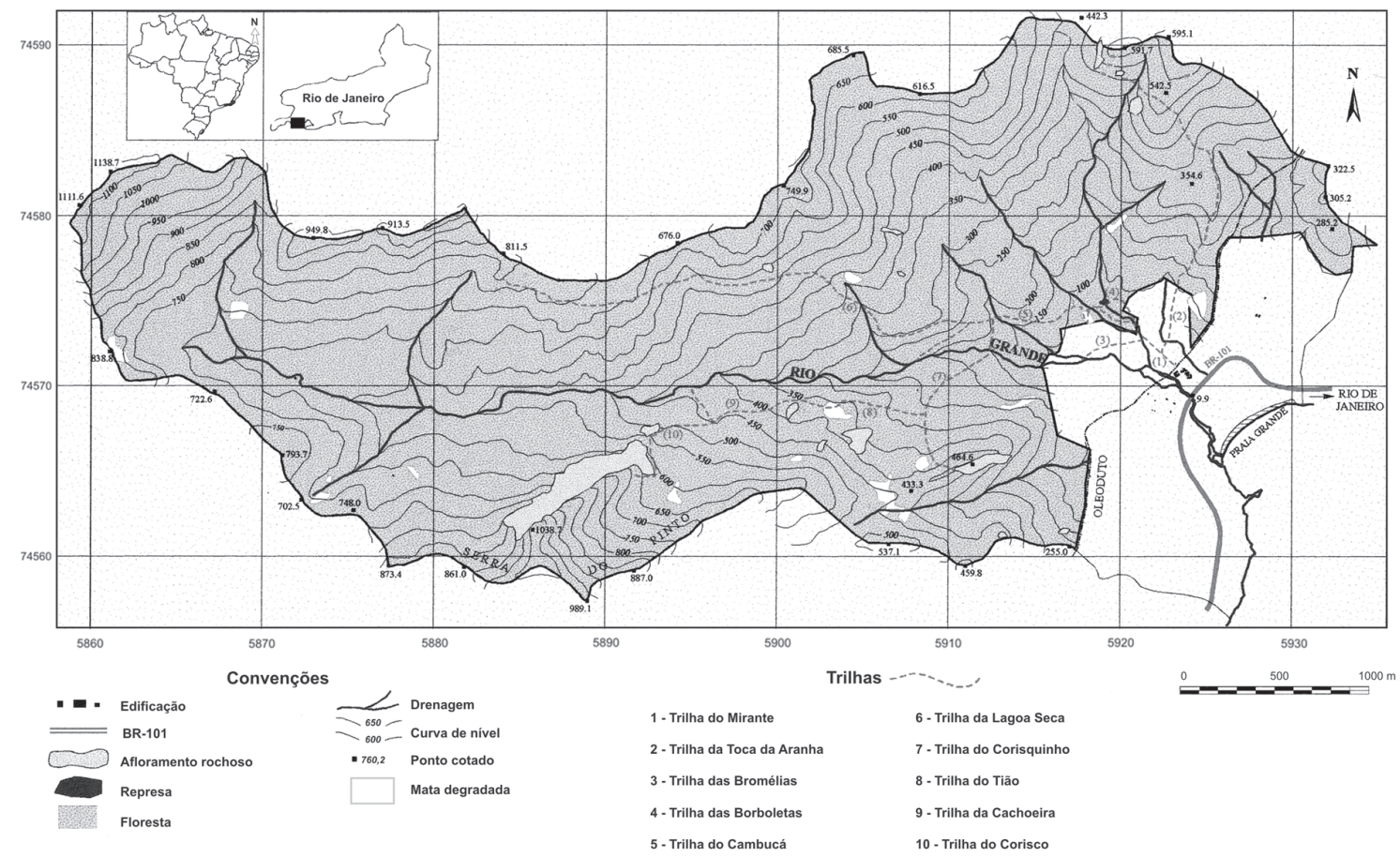

Figura 1-Mapa da Reserva Rio das Pedras, Mangaratiba, Rio de Janeiro. Modificado de Agrofoto Aerofotogrametria S/A (1999). Figure 1 - Map of Rio das Pedras, Mangaratiba, Rio de Janeiro. Adapted from Agrofoto Aerofotogrametria S/A (1999). 
tomentosos ou glabros, tricomas simples ou fasciculados. Estípulas, geralmente caducas. Folhas alterno-espiraladas ou dísticas, pecioladas, simples; lâminas membranáceas ou cartáceas, inteiras ou lobadas, raramente glabras, às vezes com nectários na face dorsal. Flores solitárias ou em inflorescências de diversos tipos, terminais ou axilares; actinomorfas, hermafroditas; epicálice presente ou ausente; cálice gamossépalo, 5 sépalas; 5 pétalas adnatas à base do tubo estaminal; numerosos estames monadelfos, com os estames frequentemente apresentando partes livres diversamente distribuídas ao longo do tubo, anteras reniformes, biesporangiadas, monotecas, rimosas; ovário súpero, 3-muitos lóculos, 1-muitos óvulos; estiletes livres entre si ou parcialmente concrescidos e depois liberando-se em tantos ramos quantos forem os carpelos ou em dobro do número deles; estigmas capitados. Frutos esquizocárpicos; mericarpos trígonos, múticos, bi ou triaristados; sementes glabras ou pilosas.

\section{Chave para o reconhecimento das espécies de Malvaceae s. str. na Reserva Rio das Pedras}

1. Flores e frutos com epicálice.

2. Nectário bem desenvolvido na face abaxial da lâmina foliar; mericarpos gloquideados

2'. Nectário ausente na face abaxial da lâmina foliar; mericarpos nunca gloquideados.

3. Epicálice com três bractéolas; mericarpos comprimidos lateralmente, em forma de cunha ..... Malvastrum coromandelianum

3'. Epicálice com mais de três bractéolas; mericarpos trígonos

Pavonia sepium

1'. Flores e frutos sem epicálice.

4. Inflorescências em racemos contraídos, axilares; cálice de base arredondada e flores com até 15 estames Sidastrum micranthum

4'. Inflorescências corimbosas, glomérulos axilares ou flores solitárias; cálice geralmente de base 5costada ou campanulada, flores com mais de 20 estames.

5. Subarbustos a arbustos eretos ou decumbentes; cálice costado.

6. Lâminas foliares lineares; inflorescências corimbosas Sida linifolia

6'. Lâminas foliares rômbicas, lanceoladas ou ovadas; inflorescências em glomérulos axilares ou flores solitárias.

7. Arbustos decumbentes; inflorescências em glomérulos axilares; esquizocarpo com cinco mericarpos Sida urens

7'. Arbustos eretos; inflorescências em glomérulos axilares ou flores solitárias; esquizocarpo com sete ou mais mericarpos.

8. Estípulas largo-lineares, 3-nervadas; folhas dísticas, margem serreada, ciliada Sida planicaulis

8. Estípulas lineares; folhas alterno-espiraladas; margem completamente serreada ou serreada apenas na porção mediana superior.

9. Margem da lâmina foliar completamente serreada; corola ca. 1,2 cm diâm; esquizocarpo com 10-13 mericarpos Sida santaremensis

9'. Margem da lâmina foliar serreada apenas na porção mediana superior; corola ca. 1 cm diâm.; esquizocarpo com 8-10 mericarpos.

10. Folhas com pecíolos ca. $5 \mathrm{~cm}$ compr.; lâmina foliar de face adaxial pubescente; esquizocarpo com mericarpos bi-aristados Sida rhombifolia

10'. Folhas com pecíolos ca. $1 \mathrm{~cm}$ compr.; lâmina foliar de face adaxial velutina; esquizocarpo com mericarpos múticos ...... Sida glaziovii

5'. Arbustos eretos; cálice não costado.

11. Lâmina foliar peltada ou de base cordado-imbricada Abutilon peltatum

11'. Lâmina foliar nunca peltada, base profundamente cordada ou sub-cordada.

12. Ramos velutinos; cálice profundamente lobado, abaixo da região mediana; mericarpos levemente aristados Abutilon sellowianum

12'. Ramos pubérulos ou glabros; cálice lobado até a região mediana; mericarpos múticos Abutilon bedfordianum 
Abutilon bedfordianum (Hook.) A. St. -Hil. \& Naud., Ann. Sc. Nat. 2(18): 48. $1842 . \quad$ Fig. 2 a-d Sida bedfordiana Hook., Bot. Mag. 68, t. 3892. 1841.

Arbusto ereto 1,5-2 m alt. Ramos cilíndricos, pubérulos ou glabros. Estípulas ca. $1 \mathrm{~cm}$ compr., lineares, pubérulas, tricomas fasciculados. Folhas alterno-espiraladas com pecíolos 2-18 cm compr., glabros; lâmina foliar 5-25×3-21 cm, verde concolor, membranácea, cordiforme, base cordada, às vezes subcordada, ápice agudo a cuspidado, margem serreada; face adaxial pubérula ou glabra, tricomas glandulares sésseis e raros fasciculados, face abaxial pubescente, tricomas fasciculados. Inflorescências axilares em cimeiras 2-4 floras; antopódio 5-6 cm compr., pubescente. Flores com pedicelo ca. $5 \mathrm{~mm}$ compr., pubescente; epicálice ausente; cálice ca. 1,5 cm compr., não costado, lobado até a região mediana, ca. $0,8 \mathrm{~cm}$ compr., levemente cuspidados, tomentoso externamente, tricomas fasciculados; corola ca. $4,5 \mathrm{~cm}$ diâm., amarelada com nervuras vinosas; estames mais de 20, filetes parcialmente concrescidos ca. $0,7 \mathrm{~cm}$ compr., formando um tubo glabro, porção livre dos estames aprox. 0,4 cm compr.; ovário 13-15 locular, 5-6 óvulos por lóculo; estilete ca. 1,2 cm compr. Esquizocarpo ca. 1,5 cm diâm.; 13-15 mericarpos ca. $1 \times 0,7 \mathrm{~cm}$, múticos, tricomas simples diminutos e fasciculados. Sementes 5-6 com tricomas simples. Material examinado: trilha para a Lagoa Seca, 200-400 m, 27.V.1997, fl., M.G. Bovini et al. 1183 (RB, RUSU). Material adicional examinado: Rio de Janeiro, Itatiaia, 1500 m, 29.V.1935, fl. e fr., A. Brade 14607 (RB).

Espécie de distribuição exclusiva da Região Sudeste do Brasil. Na RRP ocorreu em locais ciófilos em poucas populações.

Abutilon bedfordianum possui uma grande plasticidade em relação ao porte e coloração da folhas. Há registros em materiais de herbários de indivíduos com 6 metros de altura e folhas bastante discolores. A partir desta segunda característica, Fries (1908) atribuiu-lhe algumas variedades. Esta espécie caracteriza-se por possuir uma pilosidade quase imperceptível nos ramos e folhas, lâminas foliares com a base cordiforme a sub-cordiforme, corola com nervuras vinosas e mericarpos múticos com 5-6 sementes.

Abutilon peltatum K. Schum., Fl. bras. 12(3): 398. 1891.

Fig. $2 \mathrm{e}-\mathrm{g}$

Iconografia: Schumann (1891), tab. 72.

Arbusto ereto 1,5-2,0 m alt. Ramos cilíndricos, pubescentes, tricomas glandulares e simples e longos. Estípulas ca. $1 \mathrm{~cm}$ compr., largo-lineares, indumento e tricomas iguais aos dos ramos. Folhas alternoespiraladas com pecíolos 3-4 cm compr., indumento e tricomas iguais aos dos ramos; lâmina foliar 4-12,5 $\times 3-8,5 \mathrm{~cm}$, verde concolor, membranácea, cordiforme, frequentemente peltada ou com a base cordadoimbricada, ápice agudo, margem serreada; face adaxial pubescente, tricomas simples e poucos fasciculados, face abaxial velutina, tricomas simples longos e poucos fasciculados. Flores axilares, solitárias; antopódio ca. $2 \mathrm{~cm}$ compr., pubescente; epicálice ausente; cálice ca. $2 \mathrm{~cm}$ compr., não costado, lobado até abaixo da região mediana, ca. 1,8 cm compr., velutino externamente, tricomas simples e fasciculados; corola ca. $5 \mathrm{~cm}$ diâm., amarela; estames mais de 20, filetes parcialmente concrescidos ca. 2 cm compr., formando um tubo glabro, porção livre dos estames aprox. $1 \mathrm{~cm}$ compr.; ovário 8-9 locular, 4-5 óvulos por lóculo; estilete ca. $3 \mathrm{~cm}$ compr. Esquizocarpo ca. $2 \mathrm{~cm}$ diâm.; 8-9 mericarpos ca. 1,5 $\times 0,7 \mathrm{~cm}$, levemente aristados, tricomas simples e fasciculados. Sementes 4-5 com tricomas simples. Material examinado: trilha para o Pico do Corisco, 750 m, 25.V.2000, fl. e fr., M.G. Bovini et al. 1801 (RB, RUSU).

Ocorre nos estados de Minas Gerais, Rio de Janeiro e São Paulo. Na RRP, devido ao difícil acesso, foi encontrada em local protegido com população bastante reduzida, sobre rochas e com forte incidência solar.

Abutilon peltatum caracteriza-se por possuir lâminas foliares peltadas ou cordado-imbricadas e tricomas glandulares e simples longos nos ramos. Assemelha a A. fluviatile (Vell.) K. Schum., o que causa enganos nas identificações dos espécimes. A princípio, o indumento e a forma da lâmina foliar, diferem as duas espécies. Sem dúvida, estudos abordando estes táxons esclareceriam a validade dos mesmos como táxons distintos ou sinônimos.

\footnotetext{
Abutilon sellowianum (Klotzsch) Regel, Ind. Semin. Hort. Bot. Petrop. 51. $1860 . \quad$ Fig. 2 h-k Sida sellowiana Klotzsch in Otto \& Dietrich, Allgem. Gartenzeitung 4: 9. 1836.

Iconografia: Monteiro-Filho (1955), fig. 6; Sodré (1989), fig. 1.

Arbusto ereto 1,5-2 m alt. Ramos cilíndricos, velutinos, tricomas fasciculados. Estípulas $0,7-1 \mathrm{~cm}$ compr., largo-lineares, velutinas, tricomas fasciculados e raros simples longos. Folhas alterno-espiraladas com pecíolos 4-21 cm compr., indumento e tricomas iguais aos das estípulas; lâmina foliar 7-34×5,5-24 cm, verde discolor, membranácea, cordiforme, às vezes trilobada, base profundamete cordada, ápice agudo a cuspidado, margem serreada; face adaxial velutina, tricomas
} 

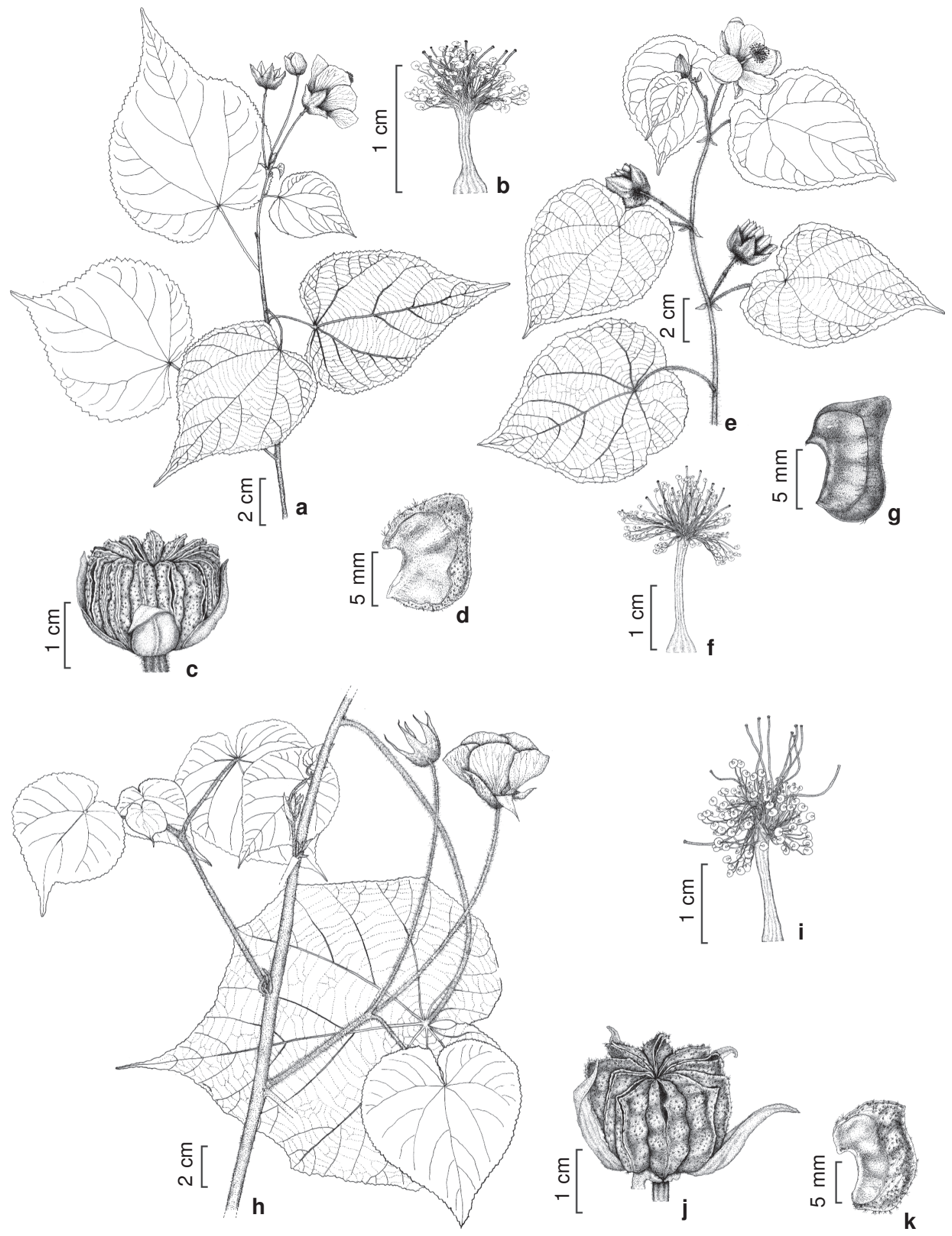

Figura 2 - a-d. Abutilon bedfordianum - a. ramo fértil; b. tubo estaminal; c. fruto; d. mericarpo. e-g. A. peltatum - e. ramo fértil; f. tubo estaminal; g. mericarpo. h-k. A. sellowianum -h. ramo fértil; i. tubo estaminal; j. fruto; k. mericarpo. (a-b Bovini et al. 1183; c-d Brade 14607; e-g Bovini et al. 1801; h-k Bovini et al. 1872).

Figure 2 - a-d. Abutilon bedfordianum - a. flowering branch; b. staminal column; c. fruit; d. mericarp. e-g. A. peltatum - e. flowering branch; f. staminal column; g. mericarp. h-k. A. sellowianum - h. flowering branch; i. staminal column; j. fruit; k. mericarp. (a-b Bovini et al. 1183; c-d Brade 14607; e-g Bovini et al. 1801; h-k Bovini et al. 1872). 
multiradiados e simples, face abaxial densamente velutina, tricomas fasciculados. Inflorescências axilares em cimeiras 2-4 floras, às vezes flores solitárias; antopódio 5-16 cm compr., velutino. Flores com pedicelo aprox. $5 \mathrm{~mm}$ compr., velutino; botões com sépalas acuminadas; epicálice ausente; cálice ca. $1,7 \mathrm{~cm}$ compr., não costado, lobado até abaixo da região mediana, ca. $2 \mathrm{~cm}$ compr., velutino externamente, tricomas fasciculados; corola ca. $5 \mathrm{~cm}$ diâm., rósea; estames mais de 20, filetes parcialmente concrescidos ca. 1,5 cm compr., formando um tubo glabro, porção livre dos estames aprox. $5 \mathrm{~mm}$ compr.; ovário 10-15 locular, 3 óvulos por lóculo; estilete ca. 2,3 cm compr. Esquizocarpo ca. 2 cm diâm.; 10-15 mericarpos ca. $1,2 \times 0,5 \mathrm{~cm}$, levemente aristados, tricomas fasciculados. Sementes 3-4 com tricomas simples.

Material examinado: trilha para o Pico do Corisco, 300 m, perto de riacho, 13.VI.2000, fl. e fr., M.G. Bovini et al. 1872 (RB, RUSU).

Material adicional examinado: RIO DE JANEIRO: Rio de Janeiro, Corcovado, 18.I.1972, fl., D. Sucre 8237 (RB); Jacarepaguá, Represa do Camorim, 28.VII.1988, fl., L.C. Giordano et al. 438 (RB).

Restrita aos estados de Minas Gerais e Rio de Janeiro, preferencialmente acima de 500 metros de altitude em Mata Atlântica. Na RRP foi encontrada no estrato arbustivo em mata úmida.

Monteiro-Filho (1955) combinou Abutilon sellowianum em Backeridesia, com base nas características dos mericarpos. Como ainda não há um estudo detalhado para o gênero Backeridesia no Brasil, adotou-se neste artigo tal espécie ainda como pertencente ao gênero Abutilon. A mesma é caracterizada pelas folhas de grandes dimensões, botões com sépalas acuminadas e o cálice profundamente lobado.

Malvastrum coromandelianum (L.) Garcke subsp. coromandelianum, Bonplandia 5: 295. 1857. Fig. 3a Malva coromandeliana L., Sp. Pl. ed. 1, 2: 687.1753.

Iconografia: Hill (1982), figs. 63-64; Bovini (2001a), fig. 3 .

Subarbusto ereto 0,6-1,5 malt. Ramos cilíndricos, hirsutos, tricomas fasciculados (4 raios), adpressos. Estípulas ca. $5 \mathrm{~mm}$ compr., lineares a lanceoladas, hirsutas, tricomas simples e fasciculados. Folhas alterno-espiraladas com pecíolos 1-2 cm compr., indumento e tricomas iguais aos dos ramos; lâmina foliar 3-6,5 ×1,5-3 cm, sem nectário, verde concolor, membranácea, ovada a lanceolada, base aguda a cuneada, ápice agudo, margem serreada, face adaxial hirsuta, tricomas simples, raros fasciculados (iguais aos dos ramos), face abaxial hirsuta, tricomas iguais aos dos ramos. Inflorescências em racemos reduzidos, axilares, frequentemente solitárias. Flores com pedicelo ca. $2 \mathrm{~mm}$ compr., hirsuto, tricomas iguais aos dos ramos; epicálice 3 bractéolas, ca. 4 mm compr., livres, hirsutas, tricomas simples; cálice ca. $5 \mathrm{~mm}$ compr., lobado até a região mediana, hirsuto externamente, tricomas iguais aos dos ramos; corola ca. $1 \mathrm{~cm}$ diâm., amarela; estames mais de 20, filetes parcialmente concrescidos ca. $2 \mathrm{~mm}$ compr., formando um tubo glabro, porção livre dos estames ca. $1 \mathrm{~mm}$ compr.; ovário 10-14 locular, 1 óvulo por lóculo; estilete ca. $4 \mathrm{~mm}$ compr. Esquizocarpo aprox. $6 \mathrm{~mm}$ diâm.; 10-14 mericarpos ca. $3 \times 3$ mm, comprimidos lateralmente em forma de cunha, 3-aristados, arista apical ca. $1 \mathrm{~mm}$ compr. e laterais pouco menores que 1 mm compr., tricomas simples longos entre as aristas. Semente única, glabra.

Material examinado: atrás do alojamento, perto do viveiro de mudas, 23.XI.1999, fl. e fr., M.G. Bovini et al. s.n. (RB 392087, RUSU).

Material adicional examinado: RIO DE JANEIRO: Silva Jardim, REBIO de Poço das Antas, 30.VIII. 1994, fl. e fr., J.M.A. Braga et al. 1306 (RB).

Pantropical, ocorrendo principalmente na costa oeste da América do Sul até o nordeste da Argentina, mas de acordo com Fryxell (1988) estende-se até as zonas temperadas. Na RRP, foi encontrada ao lado do alojamento em populações isoladas, sob intensa ação antrópica.

Um caráter marcante do gênero Malvastrum são os tricomas fasciculados com quatro raios adpressos na maioria de suas estruturas. Malvastrum coromandelianum pode ser confundida com Sida planicaulis, mas o indumento das estruturas vegetativas com tricomas fasciculados (4 raios) e raramente simples, 3 bractéolas no epicálice e mericarpos 3-aristados, sendo a arista apical maior, a caracterizam.

Pavonia sepium A. St. -Hil., Fl. bras. merid. 1: 225. 1827.

Iconografia: Gürke (1892), tab. 86; Esteves (2001), fig. 20.

Subarbusto a arbusto ereto 0,5-1,5 m alt. Ramos cilíndricos, pubérulos, tricomas fasciculados. Estípulas ca. $5 \mathrm{~mm}$ compr., lineares, pubérulas, tricomas simples e fasciculados. Folhas alterno-espiraladas, com pecíolos ca. 1,5 cm compr., indumento e tricomas iguais aos dos ramos; lâmina foliar 2,5-11×1-4,5 cm, sem nectário, verde concolor, membranácea, ovada a lanceolada, base arredondada, às vezes, obtusa, ápice agudo, margem serreada, face adaxial praticamente glabra, raros tricomas fasciculados, face abaxial 


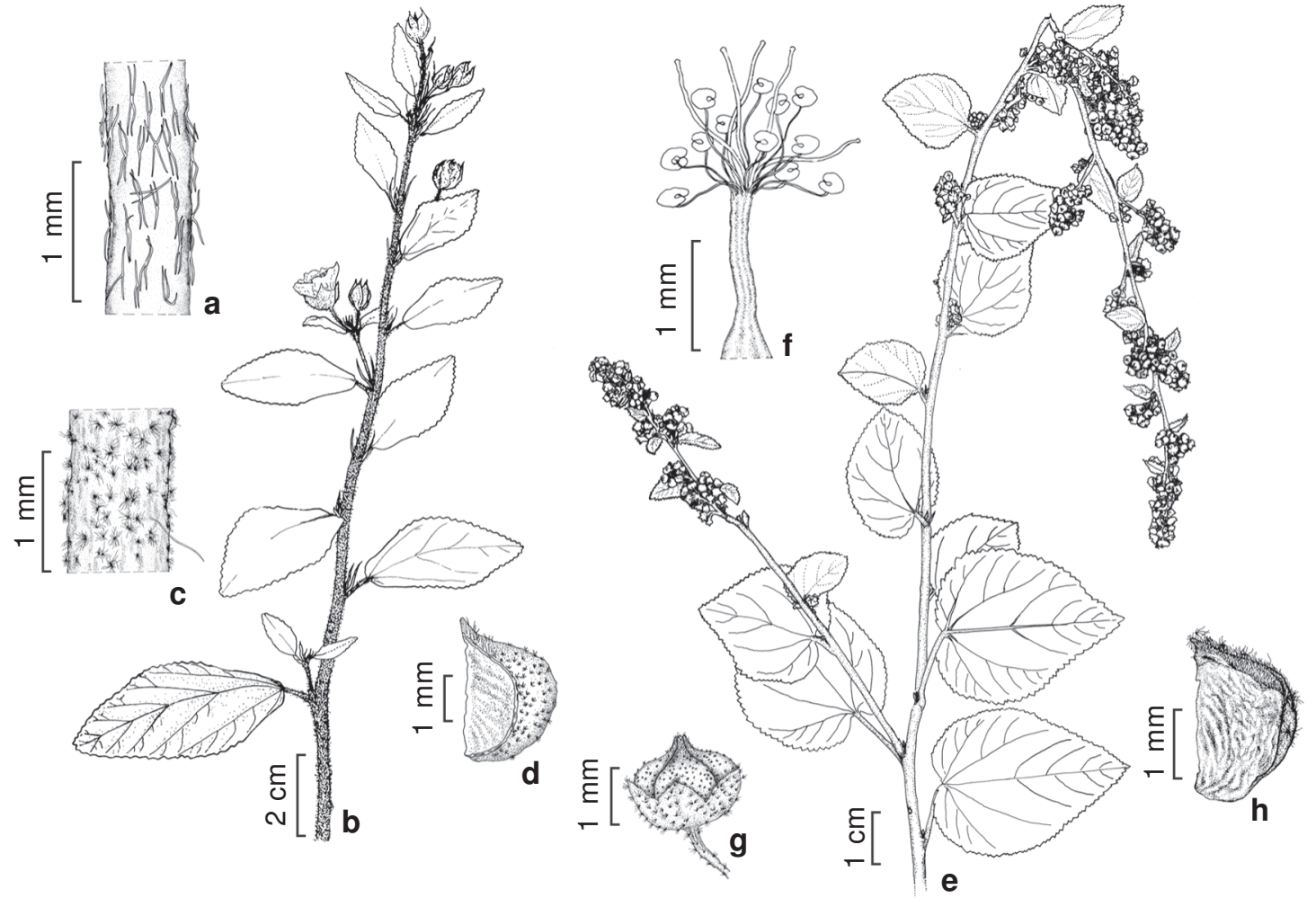

Figura 3 - Malvastrum coromandelianum - a. detalhe do ramo. b-d. Sida glaziovii - b. ramo fértil; c. detalhe do ramo; d. mericarpo. e-h. Sidastrum micranthum - e. ramo fértil; f. tubo estaminal; g. fruto; h. mericarpo. (a Bovini s.n. et al. RB392087; b-d Bovini et al. 2804; e-h Bovini et al. 1115).

Figure 3 - Malvastrum coromandelianum - a. detail of branch. b-d. Sida glaziovii - b. flowering branch; c. detail of branch; d. mericarp. e-h. Sidastrum micranthum - e. flowering branch; f. staminal column; g. fruit; h. mericarp. (a Bovini s.n. et al. RB392087; b-d Bovini et al. 2804; e-h Bovini et al. 1115).

levemente pubérula, tricomas fasciculados. Inflorescências axilares em mônades (flor solitária). Flores com pedicelo 3-6 cm compr., pubescente, tricomas simples e fasciculados; epicálice 5-7 bractéolas, ca. $7 \mathrm{~mm}$ compr., conatas somente na base, pubescentes, tricomas simples e fasciculados; cálice 5-6 mm compr., lobado até abaixo da região mediana, pubescente externamente, tricomas fasciculados; corola ca. 1,2 cm diâm., amarela; estames mais de 20, filetes parcialmente concrescidos ca. 4 mm compr., formando um tubo glabro, porção livre dos estames ca. $1 \mathrm{~mm}$ compr., distribuídos ao longo do tubo; ovário 5 locular, 1 óvulo por lóculo; estilete ca. $6 \mathrm{~mm}$ compr. Esquizocarpo aprox. $6 \mathrm{~mm}$ diâm.; 5 mericarpos ca. $5 \times 3 \mathrm{~mm}$, trígonos, 3 -aristados, arista central ca. $3 \mathrm{~mm}$ compr., aristas laterais $5 \mathrm{~mm}$ compr., tricomas retrorsos, faces laterais lisas. Semente única glabra.
Material examinado: trilha do Cambucá, 17.VIII.1996, fr., M.G. Bovini et al. 1022 (RB, RUSU); trilha para a Lagoa Seca, 70-800 m, 14.VIII.1999, fr., M.G. Bovini et al. 1669 (RUSU).

Pavonia sepium é amplamente distribuída na América do Sul, à exceção do Chile. Na RRP, poucas populações foram encontradas em locais sombreados nas principais trilhas.

Fryxell (1999) comenta que Cavanilles (1787) e Gürke (1892) a confundiram com P. spinifex (L.) Cav., a qual não ocorre no Brasil. Posteriormente este engano permaneceu também em Krapovickas (1978). Sabe-se portanto, que $P$. sepium pertence a um "complexo" (P. narcissi, $P$. ramosissima, $P$. sepioides, $P$. spinifex e $P$. uniflora) ainda não resolvido. Os tricomas fasciculados na face abaxial, as flores amarelas e os mericarpos 3-aristados são características que auxiliam a delimitação da espécie. 
Sida glaziovii K. Schum., Fl. bras. 12(3): 322. 1891.

Fig. 3 b-d

Iconografia: Monteiro-Filho (1936), tab. 3; Bovini (2001a), fig. 4.

Subarbusto ereto 0,5-1,5 m alt. Ramos cilíndricos, tomentosos, tricomas simples longos e multiradiados. Estípulas 6-7 mm compr., lineares, indumento e tricomas iguais aos dos ramos. Folhas alterno-espiraladas, com pecíolo ca. $1 \mathrm{~cm}$ compr., indumento e tricomas iguais aos dos ramos; lâmina foliar 1-4×0,6-3,5 cm, verde discolor, membranácea, rômbica a levemente obovada, base aguda a obtusa, ápice agudo a obtuso, margem na porção mediana superior irregularmente serreada e inferior inteira; face adaxial velutina, tricomas multiradiados, face abaxial densamente velutina, tricomas multiradiados. Inflorescências em glomérulos axilares, raramente flores solitárias; antopódio ca. 3 mm compr., tomentoso. Flores com pedicelo aprox. $1 \mathrm{~cm}$ compr., tomentosos; epicálice ausente; cálice costado, 8-9 mm compr., lobado até a região mediana, agudos, tomentoso externamente, tricomas multiradiados; corola ca. $1 \mathrm{~cm}$ diâm., amarelo-clara, com mácula vinosa na fauce; estames mais de 20, filetes parcialmente concrescidos ca. 2 mm compr., formando um tubo glabro, porção livre dos estames aprox. $1 \mathrm{~mm}$ compr.; ovário 1 óvulo por lóculo; estilete ca. $3 \mathrm{~mm}$ compr. Esquizocarpos aprox. 5 mm diâm.; 9-10 mericarpos ca. $3 \times 2$ mm, ápice com tricomas simples e fasciculados, múticos, trígonos, faces laterais marginalmente reticuladas. Semente única, com tricomas na região do hilo.

Material examinado: trilha do Cambucá, 17.V.1997, fl. e fr., M.G. Bovini et al. s.n. (RB 360329, RUSU); trilha para a Lagoa Seca, 150 m, 22. IX. 2009, fl., M.G. Bovini et al. 2804 (RB).

Ocorre preferencialmente na Região Sudeste do Brasil, com raras ocorrências na Região CentroOeste, habitando várias altitudes e ambientes. $\mathrm{Na}$ RRP foi encontrada na beira da trilha.

Sida glaziovii é caracterizada pelo indumento tomentoso em toda a planta, além de possuir uma coloração verde-clara nas lâminas foliares, diferenciandose de $S$. rhombifolia, espécie mais próxima.

Sida linifolia Cav., Diss. 1: 14. t.2. f.1. 1785.

Iconografia: Schumann (1891), tab. 57; Monteiro-Filho (1936), tab. 1; Rodrigo (1944), fig. 13, t. 27; Ugborogho (1980), fig. 1, 1a; Fuertes (1995), fig.1; Sivarajan \& Pradeep (1996), fig. 106; Bovini (2001a), fig. 5.

Subarbusto ereto 0,5-1,5 malt. Ramos cilíndricos, hirsutos, tricomas simples longos e raro fasciculados.
Estípulas ca. $5 \mathrm{~mm}$ compr., filiformes a lineares, indumento e tricomas iguais aos dos ramos. Folhas alterno-espiraladas, com pecíolo ca. $1 \mathrm{~cm}$ compr., indumento e tricomas iguais aos dos ramos; lâmina foliar 2-12×0,4-1,3 cm, verde discolor, membranácea, linear, base obtusa, ápice agudo, margem inteira, hirsuta em ambas as faces, tricomas simples longos. Inflorescências terminais, corimbosas; antopódio ca. 8 mm compr., hirsuto. Flores com pediceloca. 5 mm compr., densamente hirsuto; epicálice ausente; cálice costado, aprox. $6 \mathrm{~mm}$ compr., lobado até a região mediana, agudos, densamente hirsuto externamente, tricomas simples; corola ca. 1,3 cm diâm., alva, mácula vinosa na fauce; estames mais de 20, filetes parcialmente concrescidos ca. $3 \mathrm{~mm}$ compr., formando um tubo pubescente, tricomas simples, porção livre dos estames aprox. $1 \mathrm{~mm}$ compr.; ovário 7-8 locular, 1 óvulo por lóculo; estilete ca. $4 \mathrm{~mm}$ compr. Esquizocarpos 5-6 mm diâm.; 7-8 mericarpos ca. $2 \times 1 \mathrm{~mm}$, sub-múticos, trígonos, faces laterais levemente reticuladas. Semente única, puberulenta na região do hilo.

Material examinado: trilha do Cambucá, M.G. Bovini 1016 et al., fl. e fr., 17.VIII.1996 (RB, RUSU).

Material adicional examinado: Pernambuco, rio Formoso, 9.VIII.1954, fl. e fr., J. Falcão 991 (RB). Rio de Janeiro, Macaé, restinga de Carapebus, fazenda São Lázaro, 13.V.1995, fl. e fr., M.G. Bovini 780 (RB).

Ocorre na África, sul da Ásia, e do México até a América do Sul, à exceção de Chile e sul da Argentina, frequentemente em baixas altitudes. Na RRP é muito comum no início da trilha do Cambucá, em sua margem.

Sida linifolia possui folhas lineares e corola alva com mácula vinosa na fauce.

Sida planicaulis Cav., Diss. 1:24. t.3. f.11. 1785. Iconografia: Rodrigo (1944), fig. 19, 29 (como S. acuta); Sodré (1989), fig. 2 (como S. carpinifolia); Bovini (2001a), fig. 4; Krapovickas (2003), fig. 5.

Subarbusto ereto $0,5-1,8 \mathrm{~m}$ alt. Ramos aplanados, híspidos, tricomas simples longos. Estípulas ca. 9 mm compr., largo-lineares, 3-nervadas, glabras. Folhas dísticas, com pecíolo ca. 6 mm compr., indumento e tricomas iguais aos dos ramos; lâmina foliar 2,5-9 ×1-4,5 cm, verde concolor, membranácea, lanceolada, base aguda a obtusa, ápice agudo, margem serreada, ciliada, tricomas simples; face adaxial praticamente glabra, face abaxial glabra, raríssimos tricomas simples na nervura central. Inflorescências em glomérulos axilares ou flores solitárias; antopódio ca. $1 \mathrm{~mm}$ compr., pubescente. Flores com pedicelo aprox. $2 \mathrm{~mm}$ compr., pubescente; cálice costado, ca. $1 \mathrm{~cm}$ compr., lobado até a região mediana, muitas vezes sobrepostos, apiculados, 
pubescente externamente, tricomas diminutos fasciculados e simples longos nas margens; corola ca. 1 cm diâm., amarela; estames mais de 20, filetes parcialmente concrescidos ca. $1 \mathrm{~mm}$ compr. formando um tubo com raros tricomas glandulares, porção livre dos estames aprox. $1 \mathrm{~mm}$ compr.; ovário 7-10 locular, 1 óvulo por lóculo; estilete ca. $3 \mathrm{~mm}$ compr. Esquizocarpo ca. $5 \mathrm{~mm}$ diâm.; 7-10 mericarpos, ca. $2 \times 2 \mathrm{~mm}$, ápice com tricomas fasciculados, 2-aristados, aristas ca. $2 \mathrm{~mm}$ compr., trígonos, faces laterais levemente reticuladas. Semente única, com poucos tricomas simples na região do hilo. Material examinado: trilha do Cambucá, 18.VIII.1996, fl. e fr., M.G. Bovini et al. 1027 (RB, RUSU); trilha das Borboletas, 100-200 m, 09.I.1998, fl. e fr., M.G. Bovini et al. 1269 (RB, RUSU).

Amplamente distribuída no Brasil, exceto na região amazônica. Na RRP foi encontrada sempre em beiras de trilhas e abaixo de $500 \mathrm{~m}$.

Sida planicaulis é caracterizada, principalmente, pelos seus ramos aplanados, característica também possível em outras espécies desta seção (Distichifolia); estípulas 3-nervadas; lâmina quase glabra na face adaxial; e aristas dos mericarpos com aprox. $2 \mathrm{~mm}$ compr. Sua delimitação morfológica, já foi bastante discutida em relação a forma dos ramos e números de mericarpos, sendo comum observar identificações distintas em herbários, como: S. acuta ou S. carpinifolia. Estudos recentes (Krapovickas 2003) indicam que S. acuta ocorre somente no norte e nordeste do Brasil, e que S. carpinifolia é um sinônimo de $S$. planicaulis.

Algumas das iconografias citadas acima representam S. acuta, S. carpinifolia ou S. planicaulis, sendo provavelmente reconhecidas após Krapovickas (2003) como S. planicaulis.

Sida rhombifolia L., Sp. pl. 684. 1753.

Iconografia: Schumann (1891), tab. 63; Monteiro-Filho (1936), tab. 3; Rodrigo (1944), fig. 37-38, t. 28; Waalkes (1966), fig. 21; Fryxell (1985), fig. 6; Sodré (1989), fig. 3; Chiea \& Silva (1992), fig. 9-11; Sivarajan \& Pradeep (1994), fig. 2; Fuertes (1995), fig. 18; Sivarajan \& Pradeep (1996), fig. 8182, 87; Bovini (2001a), fig. 5; Krapovickas (2003), fig. 113; Verdcout (2004), fig. 1.

Subarbusto ereto $0,2-1 \mathrm{~m}$ alt. Ramos cilíndricos, pubérulos, tricomas fasciculados. Estípulas ca. $5 \mathrm{~mm}$ compr., lineares, caducas, indumento e tricomas iguais aos dos ramos. Folhas alterno-espiraladas, com pecíolo ca. $5 \mathrm{~mm}$ compr., indumento e tricomas iguais aos dos ramos; lâmina foliar $1-7,5 \times 0,5-3,5 \mathrm{~cm}$, verde discolor, membranácea a cartácea, rômbica, base aguda a obtusa, ápice agudo a obtuso, margem na porção mediana superior irregularmente serreada e inferior inteira; face adaxial pubescente, tricomas fasciculados esparsos, face abaxial velutina, tricomas fasciculados. Inflorescências em glomérulos axilares ou flores solitárias; antopódio ca. 1,5 cm compr., pubescente. Flores com pedicelo aprox. $6 \mathrm{~mm}$ compr., pubescente; cálice costado, 6-7 mm compr., lobado até a região mediana, pubescente externamente, muitas vezes sobrepostos, tricomas fasciculados; corola ca. $1 \mathrm{~cm}$ diâm., amarela; estames mais de 20, filetes parcialmente concrescidos menos que $1 \mathrm{~mm}$ compr., formando um tubo glabro, porção livre dos estames aprox. 1 mm compr.; ovário 8-10 locular, 1 óvulo por lóculo; estilete ca. $3 \mathrm{~mm}$ compr. Esquizocarpo 5-6 mm diâm.; 8-10 mericarpos, ca. $3 \times 3 \mathrm{~mm}$, quase glabro no ápice, trígonos, 2-aristados, aristas ca. $1 \mathrm{~mm}$ compr. Semente única, glabra na região do hilo.

Material examinado: trilha do Cambucá, 18.VIII.1996, fl. e fr., M.G. Bovini et al. 1026 (RUSU); próximo ao alojamento da Reserva, 23. IX. 2009, fl. e fr., M.G. Bovini et al. 2805 (RB).

Ocorre em todo o território brasileiro. Provavelmente seja a espécie de Malvaceae com mais ampla distribuição no mundo. Na RRP foi encontrada em beira de trilha sob intensa pressão antrópica.

Sida rhombifolia é caracterizada pelas folhas rômbicas com tricomas fasciculados esparsos na face adaxial, corola amarela sem mácula e os mericarpos bi-aristados. Estima-se que aproximadamente 30 nomes estejam envolvidos entre variedades e sinônimos dessa espécie. Autores como Monteiro-Filho (1936), Rodrigo (1944) e Waalkes (1966) reconhecem algumas variedades ou subespécies, e Sivarajan \& Pradeep $(1994,1996)$ as identificam como um grupo de espécies que formam um complexo.

Sida santaremensis Mont., Monogr. Malvac. Bras. Fasc. I. 1936.

Iconografia: Monteiro-Filho (1936), tab. 8; Fryxell (1985), fig. 6; Fuertes (1995), fig. 21; Bovini (2001a), fig. 6.

Subarbusto ereto 1-1,5 m alt. Ramos cilíndricos, pubérulos, tricomas fasciculados. Estípulas 6-7 mm compr., lineares, caducas, indumento e tricomas iguais aos dos ramos. Folhas alterno-espiraladas, com pecíolos ca. $7 \mathrm{~mm}$ compr., indumento e tricomas iguais aos dos ramos; lâmina foliar 2-7,5 × 1-4,2 cm, verde discolor, membranácea, 
rômbica a ovada, às vezes lanceolada, base aguda a obtusa, ápice agudo, margem serreada; face adaxial pubérula, tricomas fasciculados esparsos, face abaxial velutina, tricomas multiradiados. Inflorescências em glomérulos axilares ou flores solitárias; antopódio 2-3 mm compr., pubérulo. Flores com pedicelo aprox. $5 \mathrm{~mm}$ compr., pubérulo; cálice costado, 8-9 mm compr., lobado até a região mediana, acuminados, muitas vezes sobrepostos, pubérulo externamente, tricomas fasciculados; corola ca. 1,2 diâm., amarela; estames mais de 20, filetes parcialmente concrescidos ca. $1 \mathrm{~mm}$ compr., formando um tubo glabro, porção livre dos estames aprox. 1 mm compr.; ovário 10-13 locular, 1 óvulo por lóculo; estilete ca. $3 \mathrm{~mm}$ compr. Esquizocarpo ca. 7 mm diâm.; 10-13 mericarpos ca. $3 \times 3 \mathrm{~mm}$, quase glabro no ápice, trígonos, 2-aristados, aristas ca. $1 \mathrm{~mm}$ compr., faces laterais marginalmente reticuladas. Semente única, tricomas fasciculados na região do hilo.

Material examinado: trilha do Cambucá, proximidades do Mirante, ca. 70 m, 26.V.1998, fl. e fr., J.M.A. Braga et R. Andreata 4850 (RB, RUSU); trilha do Cambucá, perto do Mirante, 23.XI.1998, fl. e fr., M.G. Bovini et J.M.A. Braga 1571 (RB, RUSU).

Sida santaremensis ocorre em quase todo o Brasil à exceção da Região Sul, que até o momento não se tem registro. Na RRP foi vista somente no início da trilha do Mirante, com forte incidência solar.

A espécie pertence à seção Sidae por possuir 10-13 carpídios e folhas rômbicas à ovadas, embora apresente folhas com margem inteiramente crenada até a base. O cálice de grandes dimensões, fortemente 5-costado e os mericarpos possuindo as mesmas medidas comprimento $\times$ largura, também auxiliam no reconhecimento da espécie.

Sida urens L., Syst. Nat. Ed. 10. 1145. 1759.

Iconografia: Schumann (1891), tab. 60; Monteiro-Filho (1936), tab.1; Rodrigo (1944), fig. 19, 24, t. 27; Ugborogho (1980), fig. 4, 4a; Fryxell (1985), fig. 2; Fuertes (1995), fig. 3; Bovini (2001a), fig. 5; Krapovickas (2006), fig. 2.

Subarbusto decumbente. Ramos cilíndricos, hirsutos, tricomas simples longos (ca. $3 \mathrm{~mm}$ compr.) e fasciculados. Estípulas ca. $5 \mathrm{~mm}$ compr., filiformes, indumento e tricomas iguais aos dos ramos. Folhas alterno-espiraladas, com pecíolos 3-4 cm compr., indumento e tricomas iguais aos dos ramos; lâmina foliar 2-8,5 ×1-4,6 cm, verde concolor, membranácea, ovada, base cordada, ápice agudo, margem crenada; face adaxial híspida, tricomas fasciculados, face abaxial híspida, tricomas fasciculados. Inflorescências em glomérulos axilares; antopódio imperceptível. Flores com pedicelo menor que $3 \mathrm{~mm}$ compr. (subsésseis), hirsuto; cálice costado, 8-9 mm compr., lobado até a região mediana, acuminados, sobrepostos, verde escuro nas margens, hirsuto externamente, tricomas simples (ca. $3 \mathrm{~mm}$ compr.); corola ca. 1 cm diâm., amarelo-alaranjadas; estames mais de 20, filetes parcialmente concrescidos ca. $1 \mathrm{~mm}$ compr., formando um tubo pubérulo, porção livre dos estames aprox. 2 mm compr.; ovário 5 locular, 1 óvulo por lóculo; estilete ca. 5 mm compr. Esquizocarpo ca. 3 mm diâm., 5 mericarpos ca. $2 \times 2 \mathrm{~mm}$, múticos a submúticos, quase glabro no ápice, trígonos, faces laterais levemente lisas. Semente única, glabra.

Material examinado: trilha do Cambucá, 17.VIII.1996, fl. e fr., M.G. Bovini et al. 1019 (RB, RUSU).

Material adicional examinado: MINAS GERAIS: Viçosa, campus da UFV, 13.V.1982, fl., F. Silveira s.n. (RB 235997, VIC).

Sida urens ocorre em todo o território brasileiro. Na RRP foi encontrada em baixas altitudes, em locais com forte incidência solar. Como característica marcante, a espécie possui o hábito decumbente, flores subsésseis, o cálice com lóbos acuminados e verde escuros nas margens e cinco mericarpos múticos a submúticos.

Sidastrum micranthum (A. St. -Hil.) Fryxell, Brittonia 30: 451. fig. 2. $1978 . \quad$ Fig. 3 e-h Sida micrantha St.Hil., Fl. bras. Mer. 1: 190. 1827. Iconografia: Schumann (1891), tab. 59; Monteiro-Filho (1936), tab. 1; Bovini (2001a), fig. 7. Subarbusto ereto até $1,0 \mathrm{~m}$ alt. Ramos cilíndricos, hirsutos, tricomas fasciculados. Estípulas ca. $5 \mathrm{~mm}$ compr., filiformes, indumento e tricomas iguais aos dos ramos. Folhas alterno-espiraladas, com pecíolos 2-4 cm compr., indumento e tricomas iguais aos dos ramos; lâmina foliar 2,5-9 $\times 2-7,5 \mathrm{~cm}$, verde discolor, membranácea, ovada, base cordada, ápice agudo, margem crenada; face adaxial hirsuta, tricomas fasciculados, face abaxial velutina, tricomas fasciculados. Inflorescências em racemos curtos, contraídos; antopódio ca. 1 mm compr., hirsuto. Flores com pedicelo ca. $2 \mathrm{~mm}$ compr., hirsuto; cálice ca. $1 \mathrm{~mm}$ compr., base arredondada, lobado até a região mediana, hirsuto externamente, tricomas fasciculados; corola ca. 5 mm diâm., amarelo-clara; estames 10-15, filetes parcialmente concrescidos ca. 1,5 mm compr., formando um tubo glabro, porção livre dos estames ca. $1 \mathrm{~mm}$ compr.; ovário 5 locular, 1 óvulo por lóculo; estilete ca. $2 \mathrm{~mm}$ compr. Esquizocarpo ca. 4 mm diâm.; 5 mericarpos ca. $3 \times 2 \mathrm{~mm}$, múticos, tricomas fasciculados, trígonos, faces laterais levemente reticuladas. Semente única, praticamente glabra. 
Material examinado: trilha para o Corisquinho, 200-300 m, 1.XII.1996, fl. e fr., M.G. Bovini et al. 1115 (RB, RUSU). Material adicional examinado: RIO DE JANEIRO: Niterói, restinga de Itaipu, 8.VIII.1971, fl. e fr., D. Sucre 7630 (RB).

Espécie com distribuição restrita ao neotrópico, ocorrendo comumente em todas as regiões brasileiras. Na RRP sua população restringiu-se à beira da trilha para o Corisquinho.

Sidastrum micranthum é caracterizada pela lâmina foliar ovada, inflorescência em racemos contraídos, flores pequenas e corola amarelo-clara. Dentre as características diagnósticas do gênero, destacam-se as flores com pequenas dimensões, o cálice com base arredondada e o reduzido número de estames. A espécie em questão é, provavelmente, a que apresenta as menores flores dentre as do gênero.

Urena lobata L., Sp. pl. 692. 1753.

Iconografia: Gurke (1892), tab. 84; Robyns (1965), fig. 5; Fryxell (1988), fig. 111; (1992), fig. 15; Chiea \& Silva (1992), fig. 5-8; Sivarajan \& Pradeep (1996), fig. 67; Bovini (2001a), fig. 7.

Subarbusto ereto 0,5-1 m alt. Ramos cilíndricos, pubescentes, tricomas fasciculados. Estípulas ca. $3 \mathrm{~mm}$ compr., lanceolada, indumento e tricomas iguais aos dos ramos. Folhas alterno-espiraladas, com pecíolos ca. 1-2,5 cm compr., indumento e tricomas iguais aos dos ramos; lâmina foliar 1,5-10×1-8 cm compr., verde discolor, membranácea a cartácea, inteira ou 3-5 lobada, ovada a obovada, base obtusa a cordada, ápice obtuso a agudo, margem crenada ou serreada; face adaxial hirsuta, tricomas fasciculados, face abaxial tomentosa, tricomas fasciculados, um nectário bem desenvolvido sobre a nervura principal próximo à base. Inflorescências axilares, 2-3 flores em racemos reduzidos, às vezes flores solitárias; sem antopódio. Flores com pedicelo aprox. 0,5-1 cm compr., pubescente; epicálice ca. $5 \mathrm{~mm}$ compr., 5 bractéolas, lobado até abaixo da região mediana, pubescente externamente, tricomas fasciculados; cálice ligeiramente menor que o epicálice; corola ca. $1,5 \mathrm{~cm}$ diâm., rósea com mácula rosa escuro na fauce; filetes quase totalmente concrescidos ca. 1,2 cm compr., formando um tubo glabro, porção livre dos estames aprox. $1 \mathrm{~mm}$ compr.; ovário 5 locular, 1 óvulo por lóculo; estilete ca. 1,4 cm compr. Esquizocarpo ca. $8 \mathrm{~mm}$ diâm.; 5 mericarpos ca. $5 \times 4$ mm, trígonos, múticos, gloquideados, superfície com tricomas simples e fasciculados. Semente única, glabra.

Material examinado: trilha do Cambucá, 17.VIII.1996, fl. e fr., M.G. Bovini et al. 1015 (RUSU); trilha para Pico do Corisco, 13.VI.2000, fl. e fr., M.G. Bovini et al. 1881 (RB, RUSU).
Urena lobata possui distribuição Neotropical. No Brasil ocorre em todo o território nacional. Na RRP mostra-se presente em ambiente degradado e com forte incidência solar.

Para Robyns (1965) e Waalkes (1966) o gênero é monotípico, sendo apenas representado por diversas subespécies e variedades. Já Sivarajan \& Pradeep (1996) e Fryxell (2007) aceitam mais espécies, com base na forma das folhas. A lâmina ovada a obovada, o nectário bem desenvolvido na face abaxial da folha e o tubo estaminal com filetes quase totalmente concrescidos, caracterizam facilmente $U$. lobata.

\section{Consideração Finais}

Das 13 espécies de Malvaceae s. str. encontradas na RRP, dez apresentam distribuição pantropical (Malvastrum coromandelianaum, Pavonia sepium, Sida glaziovii, S. linifolia, S. planicaulis, S. rhombifolia, S. santaremensis, $S$. urens, Sidastrum micranthum e Urena lobata), e três são endêmicas da Região Sudeste do Brasil (Abutilon bedfordianum, A. peltatum e A. sellowianum).

$\mathrm{O}$ gênero Sida foi o mais representativo, com seis espécies, e pode ser considerado o mais importante, não somente pelo número de espécies, mais também pela abundância de indivíduos visualizados no campo.

Abutilon foi o segundo gênero em riqueza de espécies na RRP, embora o número de indivíduos seja menos abundante do que todos os outros gêneros ocorrentes na área. Destaca-se que Abutilon bedfordianum é neste estudo ilustrado pela primeira vez após o exemplar-tipo.

Em relação ao número de espécies de Malvaceae s. str. citadas em flórulas para o estado do Rio de Janeiro (Bovini 1994, 2001b; Esteves 1997), evidencia-se uma riqueza considerável para o grupo na RRP, provavelmente as condições favoráveis como clima, relevo e solo, associadas à coleta sistemática das Malvaceae na área, favoreceram os dados obtidos.

Os representantes de Malvaceae s. str. da RRP, predominam no estrato herbáceo, geralmente em ambientes com forte incidência solar e pressão antrópica, a exceção das espécies de Abutilon, que predominam no interior da mata. Abutilon peltatum, por apresentar distribuição restrita, e estar associado a poucos exemplares depositados em herbários, encontra-se segundo critérios da IUCN (2001) em Perigo (B2ab(iv)), demonstrando a importância de floras locais e regionais para a taxonomia e conservação. 


\section{Agradecimentos}

À Msc. Ula Vidal a infra-estrutura oferecida na RPP, Dra. Regina Andreata como coordenadora do Projeto e convite para realização deste trabalho e a Mioco Foshina as ilustrações.

\section{Referências}

Agrofoto Aerofotografia S/A. 1999. Levantamento planialtimétrico da RPPN-Reserva Rio das Pedras, km 445,5 da BR-101 (Rio-Santos). Escala 1:10.000, Município de Mangaratiba, estado do Rio de Janeiro.

Angiosperm Phylogeny Group. 1998. An ordinal classification for the families of flowering plants. Annals of the Missouri Botanical Garden 85: 531-553.

Bovini, M. G. 1994. Malvaceae. In: Lima, M.P.M. \& Guedes-Bruni, R.R. (org.). Reserva Ecológica de Macaé de Cima, Nova Friburgo - RJ: aspectos florísticos das espécies vasculares. Vol. 1. Jardim Botânico do Rio de Janeiro, Rio de Janeiro. Pp. 251-254.

Bovini, M.G. 2001a. Malvaceae A. Juss. no Parque Estadual do Rio Doce, Minas Gerais. Rodriguésia 52:17-47.

Bovini, M.G. 2001b. Malvaceae. In: Costa, A.F. \& Dias, I.C.A. (org.). Flora do Parque Nacional da Restinga de Jurubatiba e arredores, Rio de Janeiro, Brasil: listagem, florística e fitogeografia. Angiospermas, pteridófitas e algas continentais. Série Livros, 8. Universidade Federal do Rio de Janeiro, Rio de Janeiro. Pp. 89-91.

Bovini, M.G.; Esteves, G.L. \& Duarte, M.C. 2010. Malvaceae. In: Lista de Espécies da Flora do Brasil, JBRJ. Disponível em <http://floradobrail.jbrj.gov.br/ 2010/FB0001.56>.

Carvalho, L.F. \& Bovini, M.G. 2006. Solanaceae na Reserva Rio das Pedras, Mangaratiba, Rio de Janeiro, Brasil. Rodriguésia 57: 75-98.

Cavanilles, A.J. 1787. Dissertatio botânico. 3. Madrid.

Chiea, S.C. \& Silva, T.R.S. 1992. Malvaceae. In: Flora fanerogâmica da Ilha do Cardoso. Vol. 2. Pp. 4-9.

Cronquist, A. 1988. The evolution and classification of flowering plants. 2 ed. The New York Botanical Garden, Bronx, New York.

Esteves, G.L. 1997. Malvaceae. In: Marques, M.C.M.; Vaz, A.S.F. \& Marquete, R. (org.). Flórula da Apa Cairuçu, Parati, RJ: espécies vasculares. Série Estudos e Contribuições 14. Jardim Botânico do Rio de Janeiro, Ministério do Meio Ambiente. Pp. 276-282.

Esteves, G.L. 2001. O gênero Pavonia Cav. (Malvaceae) na Região Sudeste do Brasil. Boletim do Instituto de Botânica 15: 125-193.

Fries, R.E. 1908. Studien über die amerikanische Columniferenflora. Kongliga Svenska Vetenskapsakademiens Handlingar 42: 1-67.
Fryxell, P.A. 1985. Sidus Sidarum V. The North and Central American species of Sida. Sida 11: 62-91.

Fryxell, P.A. 1988. Malvaceae of Mexico. Systematic Botany Monographs 25: 1-522.

Fryxell, P.A. 1992. Malvaceae 118. In: Harling, G. \& Anderson, L. (eds.). Flora do Equador 44. Pp. 1-141.

Fryxell, P.A. 1999. Pavonia Cav. (Malvaceae). Flora Neotropica. Monograph 76: 1-284.

Fryxell, P.A. 2007. Malvaceae. In: Greuter, W. \& Rankin, R. (eds.). Flora de la República de Cuba 13:1-230.

Fuertes, F.J. 1995. Sida (Malvaceae). Flora de Colombia 17: $1-142$.

Gurke, M. 1892. Malvaceae II. In: Martius, C.F.P. \& Eichler, A.G. (ed.). Flora brasiliensis. Typographia Regia, Monachii. Vol.12. Pp. 457-596.

Hill, S.R. 1982. A monograph of the genus Malvastrum A. Gray (Malvaceae: Malveae). Rhodora 84: 1-83, 159-254, 317-409.

IUCN. 2001. IUCN Red List Categories, v.3.1 IUCN Species Survival Commission, Gland and Cambridge. 30p.

Judd, W.S. \& Manchester, S.R. 1997. Circumscription of Malvaceae (Malvales) as determined by a preliminary cladistic analysis of morphological, anatomical, palynological and chemical characters. Brittonia 49: 384-405.

Judd, W.S.; Campbell, C.S.; Kellog, E.A.; Stevens, P.F. \& Donogue, M.J. 2002. Plant systematics. A phylogenetic approach. $2^{\mathrm{a}}$ ed. Sinauer Associates, Sunderland.

Krapovickas, A. 1978. Malvaceae. In: Steyermark, J.A \& Huber, O. (eds.). Flora del Avila. Ministerio del Ambiente y de los Recursos Renovables, Caracas, Venezuela. Pags. 589-598.

Krapovickas, A. 2003. Sida sección distichifolia (Monteiro) Krapov. comb. nov., stat. nov. (Malvaceae-Malveae). Bonplandia 12: 83-121.

Krapovickas, A. 2006. Las espécies argentinas y de países vecinos de Sida secc. Nelavaga (Malvaceae, Malveae). Bonplandia 15: 5-45.

Monteiro-Filho, H.C. 1936. Monografia das Malváceas brasileiras. O gênero Sida. Rio de Janeiro. Pp. 1-56.

Monteiro-Filho, H.C. 1955. Malvaceae brasilienses novae vel criticae I. Boletim da Sociedade Portuguesa de Ciências Naturais, ser. 2, 5: 119-140.

Quinet, C.G.P. \& Andreata, R.H.P. 2005. Estudo taxonômico e morfológico das espécies de Apocynaceae Adans. na Reserva Rio das Pedras, Mangaratiba, Rio de Janeiro, Brasil. Pesquisas-Botânica 56: 13-102.

Robyns, A. 1965. Malvaceae. In: Flora do Panamá. Annals of the Missouri Botanical Garden 52: 497-598.

Rodrigo, A.P. 1944. Las especies argentinas y uruguaias del género Sida (Malvaceae). Revista Museo La Plata, sér. 2, 6: 81-212.

Schumann, K. 1891. Malvaceae I. In: Martius, C.F.P. \& Eichler, A.G. (ed.). Flora brasiliensis. Typographia Regia, Monachii. Vol. 12. Pp. 253-456. 
Sivarajan, V. V. \& Pradeep, A. K. 1994. Taxonomy of the Sida rhombifolia (Malvaceae) complex in India. Sida 16: 63-78.

Sivarajan, V.V. \& Pradeep, A.K. 1996. Malvaceae of southern peninsular India. A taxonomic monograph. Daya Publishing House, Delhi. 312p.

Sodré, D.O. 1989. Malvaceae da Reserva Florestal de FEEMA no Maciço da Tijuca, Rio de Janeiro. Albertoa 3: 1-10.

Thiers, B. Index Herbariorum: A global directory of public herbaria and associated staff. New York Botanical Garden's Virtual Herbarium. Disponível em <http:/ /sweetgum. nybg.org/ih/>. Acesso em 18 junho 2008.
Ugborogho, R.E. 1980. The taxonomy of Sida L. (Malvaceae) in Nigeria. Boletim da Sociedade Broteriana, sér.2, 54: 5-40, 99-119.

Verdcout, B. 2004. The variation of Sida rhombifolia L. (Malvaceae) in East Africa. Kew Bulletin 59: 233-239.

Vidal, U. 1995. A família Bromeliaceae na Reserva Ecológica Rio das Pedras, Mangaratiba, Rio de Janeiro, Brasil. Dissertação de Mestrado. Museu Nacional/UFRJ, Rio de Janeiro.

Waalkes, J.B. 1966. Malesian Malvaceae revised. Blumea 14: 1-213. 